\title{
DE SCHRIJFDOOS JONGE PIJNBOOMLOTEN VAN UONO JISEI
}

In deze laatste aflevering van de reeks artikelen over de Japanse lakkunst I890-I940 wordt opnieuw een werk besproken van Uono Jisei (I883- ?), de kunstenaar met wie wij de reeks ook gestart zijn. Er bestaan weinig lakdozen waarvan het ontwerp zo sterk tot in alle onderdelen is doorgevoerd als de schrijfdoos Jonge pijnboomloten. De eerste koper, die de doos in augustus I93I aanschafte, was er dan ook danig van onder de indruk. Voor ons vormt deze doos aanleiding om de belangrijkste functie van schrijfdozen, het aanmaken van inkt, en van hun bewaardozen, het bieden van bescherming tegen invloeden van buitenaf, te bespreken.

\section{Ontwerp en techniek}

De grote rechthoekige schrijfdoos heeft afgeronde hoeken; het deksel is iets boller dan dat van de meeste schrijfdozen; de opstaande randen van de doos zelf wijken iets naar binnen terug. Schrijfdozen zijn eigenlijk nooit precies vierkant, maar altijd rechthoekig, waarbij de vorm verticaal georiënteerd is.

Het deksel laat twee volgroeide pijnboomtakken zien, waaraan vele jonge loten ontspruiten (afb. I). De naalden van de volgroeide takken staan nogal schots en scheef, terwijl de naalden van de jonge loten nog mooi in het gelid staan, met een aangenaam ritmisch lijnenspel als gevolg. De takken en de loten lijken volume te hebben. Op twee plekken zijn paren dennenappels tussen de naalden verborgen. De voorstelling loopt door over de randen van het deksel en zet zich voort op de zijkanten van de doos.

De pijnboom is afgebeeld in hoogreliëf takamakie in een bestorven goudtint. De ondergrond bestaat uit een fraai glanzende zwarte lak (roiro). Op de binnenkant valt de warme chocoladebruine ondergrond op (afb. 2). Het golvende en krullende lijnenspel van het water op zowel de binnenkant van het deksel als van de doos zelf contrasteert met het rechte lijnenspel op de buitenkant van het deksel. Hier en daar verdichten de golfbewegingen zich tot draaikolken. Wanneer het draagplankje voor het schrijfgerei is weggenomen zien we op de bodem van de binnenkant hetzelfde golfpatroon als op het draagplankje. Als men alleen de inktsteen verwijdert, wordt het golfpatroon daardoor dus niet onderbroken.

Bijzonder mooi uitgevoerd is het schrijfgerei, dat bestaat uit twee penselen, een papiermesje, een papierprikker en een inktblokhouder. Alle instrumentjes hebben een ondergrond van stralende zwarte lak, waarop een zwerm plevieren staat afgebeeld (afb. 7). De decoratie van de hele binnenkant is in laagreliëf hiramakie uitgevoerd. De prikker, het mesje en de inktblokhouder zijn afgezet met geribde randen van shakudō-zilver. 


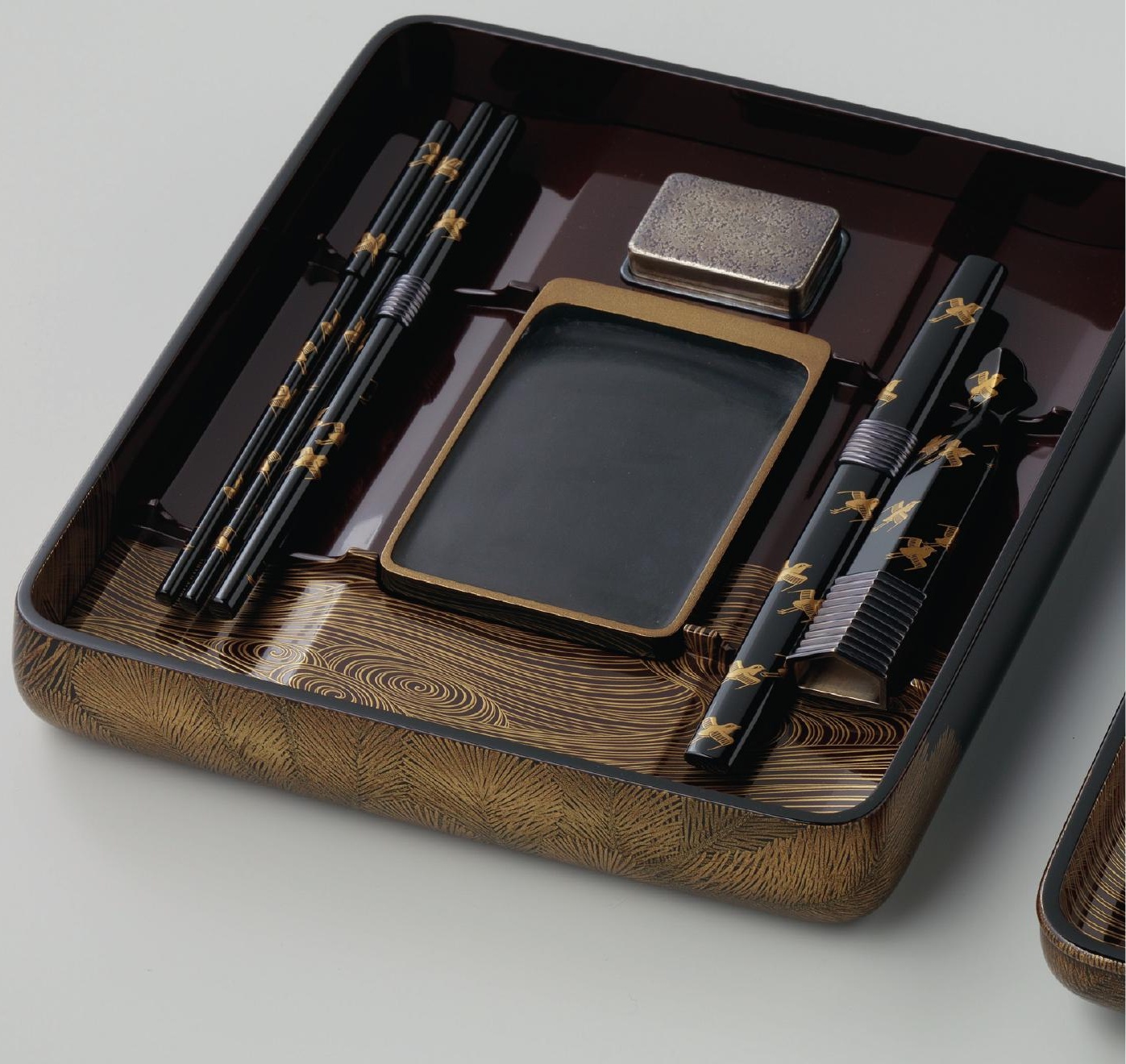




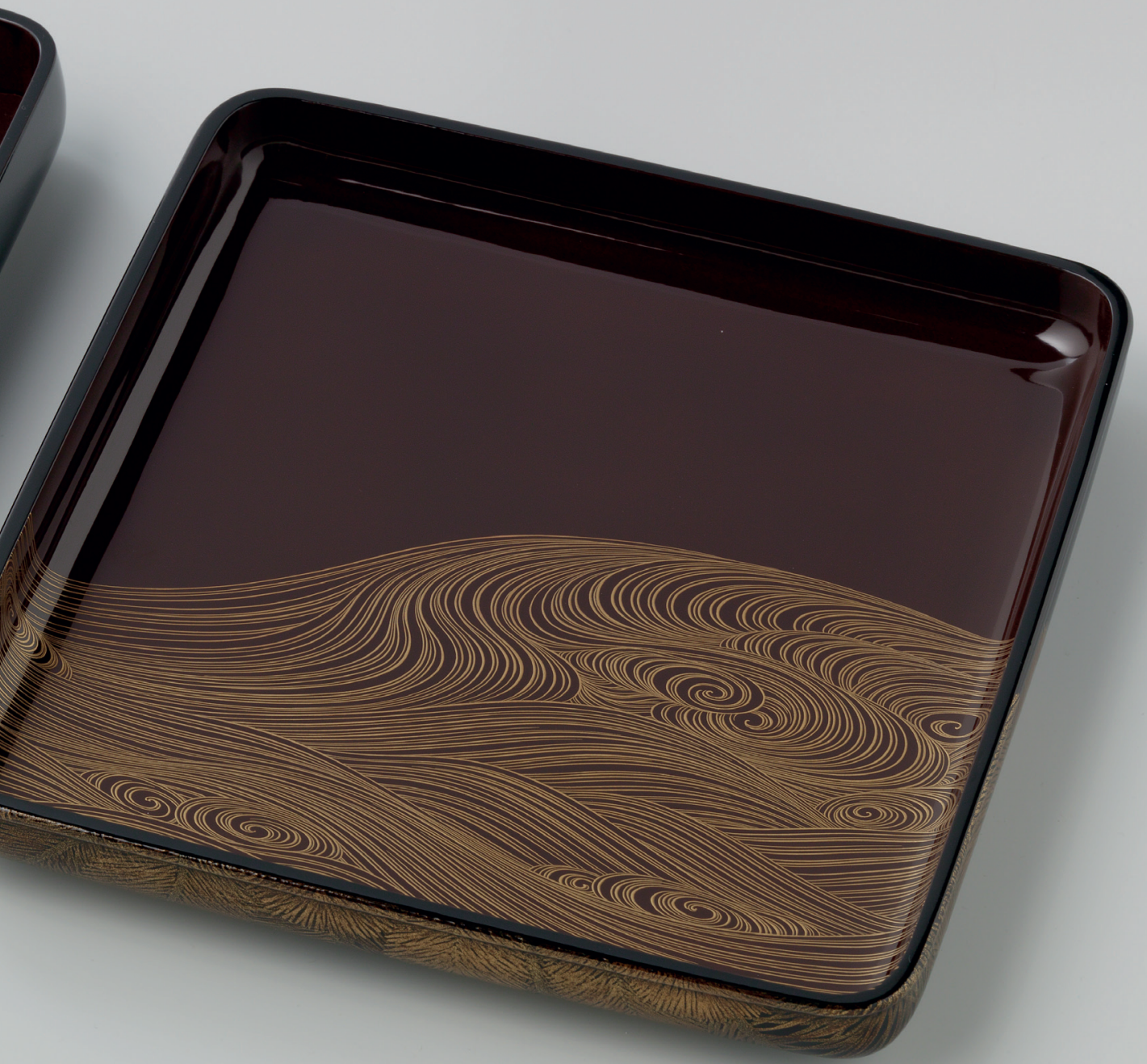


het strand kan men bijna het beurtelings aanzwellende en afnemende, vrolijke sjilpen van de plevieren horen, die over de golven scheren.

Het ontwerp van deze plek aan zee wordt nog verder doorgetrokken in de

Afb. 2 (pag. 32-33) Binnenkant van de schrijfdoos met het patroon van golven en, op het schrijfgerei, een zwerm plevieren waterdruppelaar en de inktsteen. De zilveren waterdruppelaar (gemerkt 'Kōei') representeert met zijn korrelige bovenkant het zand op het strand (afb. 3). Het meest verrassende detail komt aan het licht bij het optillen van de inktsteen: op de onderkant ervan zijn zwarte waterdruppels op de zwartgelakte ondergrond te zien, zoals op de onderkant van een steen die men opraapt uit het natte zand (afb. 4).

Op de onderkant van de schrijfdoos staat in goudlak de signatuur 'Jisei $s a k u$ ' ('gemaakt door Jisei').
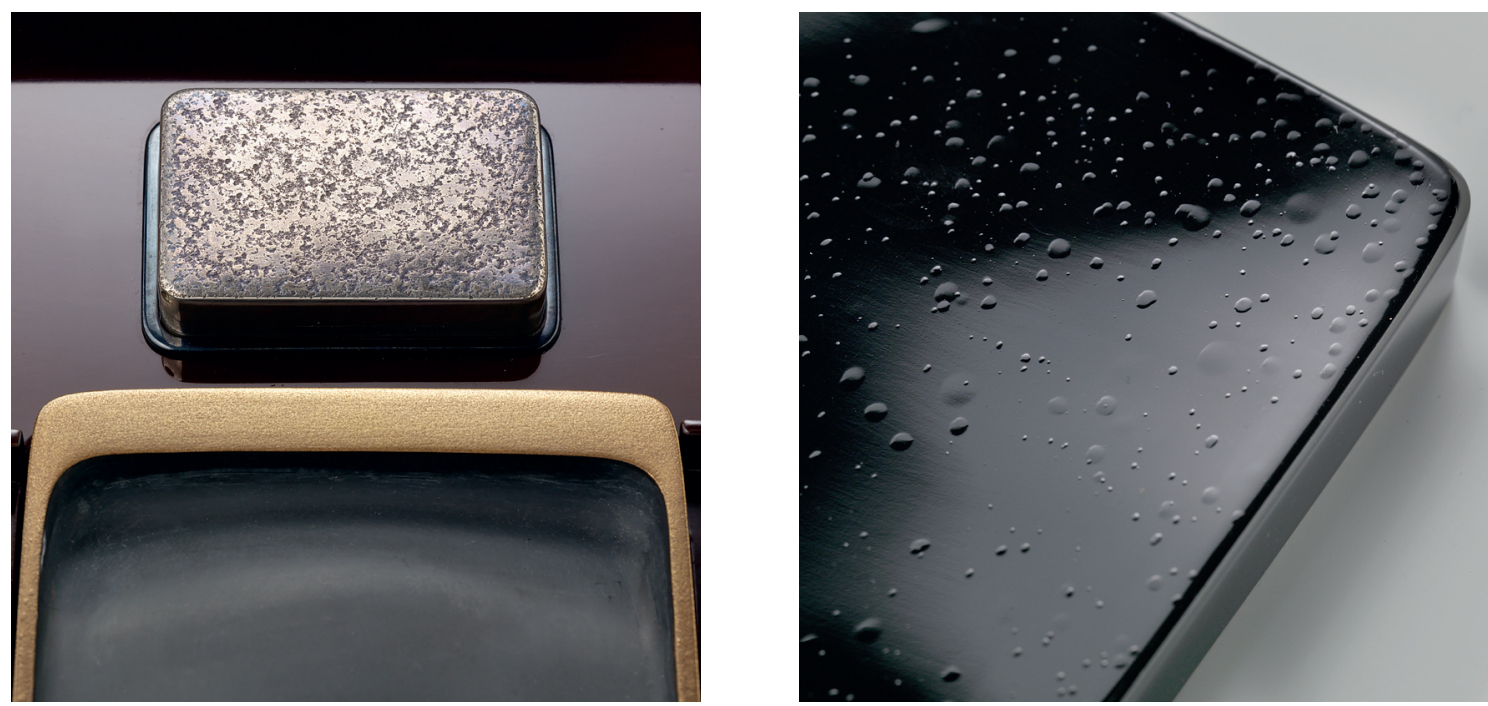

Afb. 3 (links)

Detail van de zilveren waterdruppelaar met een korrelige bovenkant, die het zandstrand symboliseert

Afb. 4 (rechts) Onderkant van de inktsteen met 'waterdruppels' afkomstig uit het natte zand

\section{Bewaardozen}

De schrijfdoos zit verpakt in twee originele bewaardozen (tomobako), waarvan de buitenste zwartgelakt is en de binnenste gemaakt is van blank paulowniahout. De schrijfdoos is gewikkeld in een ivoorkleurige zijden doek (tomogire), waarop het ronde zegel van Uono Jisei is afgedrukt. Twee bewaardozen in plaats van één gelden als een blijk van waardering voor het kunstwerk. Op het deksel van de buitenste zwartgelakte doos staat de titel Wakamatsu makie suzuribako ('makie schrijfdoos Jonge pijnboomloten') in goudlak en wederom de signatuur Jisei saku met een rond zegel 'Uono Jisei' in rode lak (afb. 5). Op het deksel van de binnenste bewaardoos wordt de titel herhaald in zwarte inkt. Op de binnenkant van het deksel is in zwarte inkt een lange tekst geschreven, die ondertekend is met twee rode zegels. ${ }^{1}$

Deze lange tekst blijkt afkomstig te zijn van de heer Sakai Kyōshin, die de schrijfdoos - blijkens zijn eigen inscriptie - in augustus I93I heeft aangeschaft nadat hij onder de indruk was geraakt van de trefzekere lijnen waarmee de pijnbomen, de golven en de meeuwen (hier vergist hij zich!) zijn weergegeven (afb. 6). Om de zomerhitte van de stad (waarschijnlijk Kyoto) te ontvluchten had hij verkoeling gezocht in de bergen. Bij toeval 01:18:22pm 
Afb. 5

Deksel van de

buitenste

bewaardoos

met de titel en

de signatuur

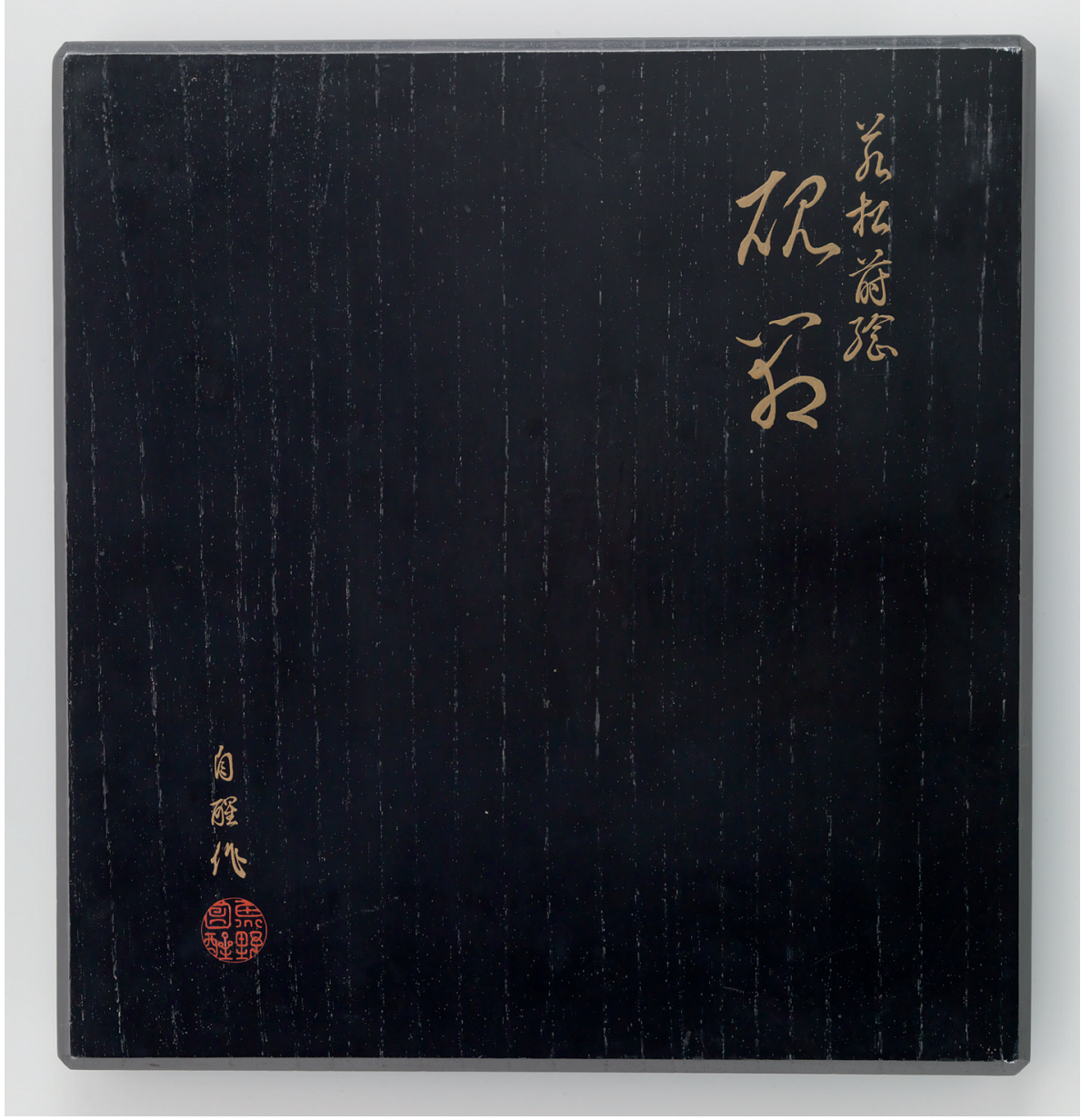

was hij toch op de tentoonstelling terechtgekomen, waar de schrijfdoos werd geëxposeerd. Hij werd bijzonder getroffen door de sublieme techniek waarmee de schrijfdoos is vervaardigd.

De tekst doet tamelijk gezwollen aan en is geschreven in het klassiek Chinees! Omdat hij daarbij gebruik maakte van nogal ongewone karaktertekens kan het vermoeden rijzen dat de nieuwe eigenaar wellicht met zijn taalkundige virtuositeit wilde pronken. Waarom heeft hij dan de plevieren voor meeuwen aangezien? Kende hij het verschil niet of was het Chinese karakter voor plevier hem onbekend?

Zoals al eerder is opgemerkt hebben de houten bewaardozen een belangrijke beschermende functie. Zij zijn bijna altijd gemaakt van paulowniahout (kiri) of van cederhout (sugi). Als de tomobako goed afsluit, voorkomt hij dat het lakobject blootstaat aan de atmosferische veranderingen van de buitenlucht. Uit proefnemingen is gebleken dat temperatuurschommelingen in de buitenlucht pas twee maanden later volledig binnenin de doos zijn doorgedrongen. Datzelfde geldt voor de luchtvochtigheid. Daardoor is het klimaat binnenin de tomobako aanzienlijk stabieler dan in de buitenlucht. Dit komt het behoud van de lakdoos bijzonder ten goede. 
Afb. 6

Inscriptie van de eerste eigenaar op de binnenkant van de binnenste bewaardoos

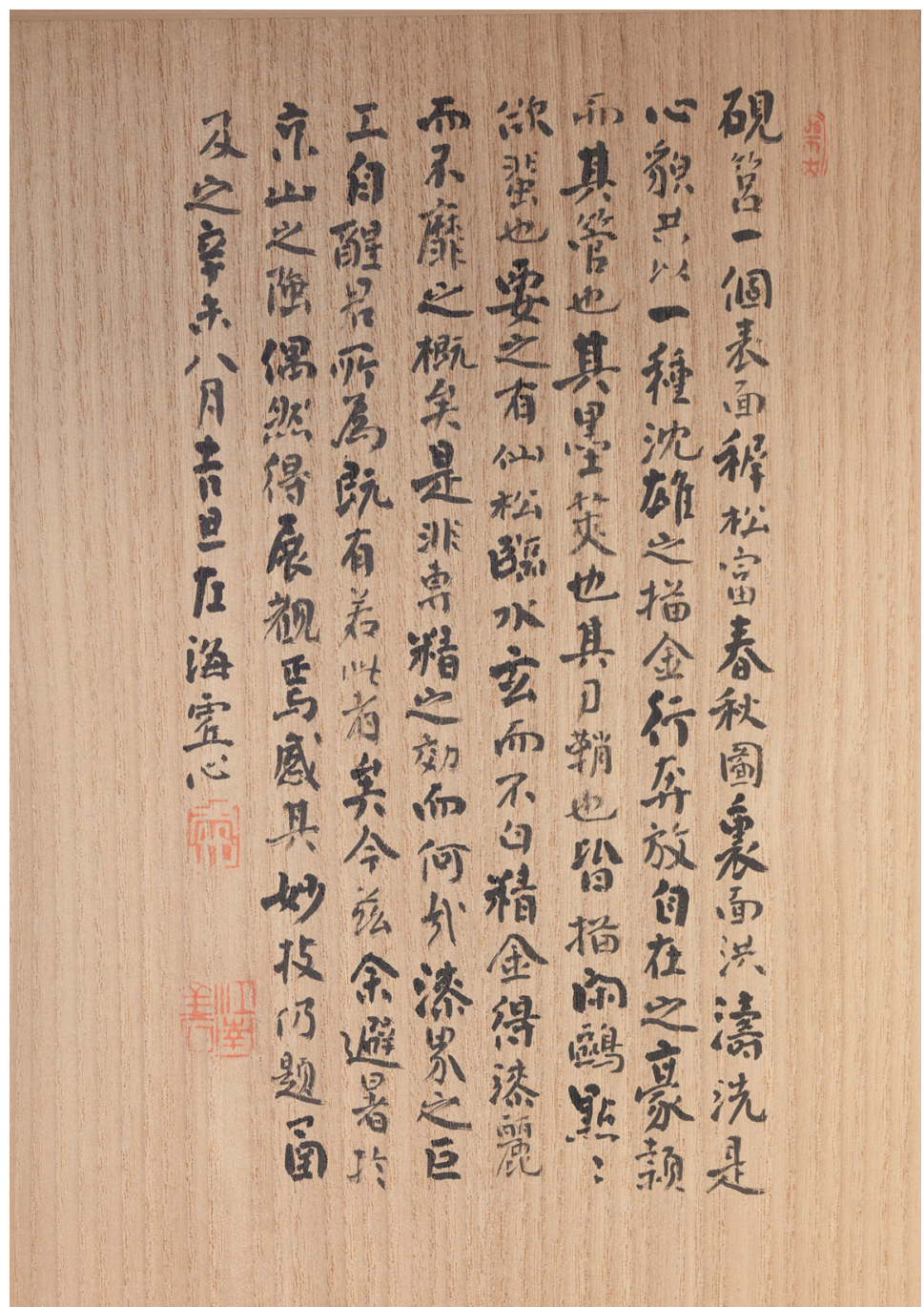

Behalve als bescherming tegen klimaatwisselingen biedt de tomobako natuurlijk ook bescherming tegen fysieke krachten, zoals stoten en blootstelling aan licht, en tegen stof of andere ongerechtigheden in de lucht. $^{2}$

De lakdoos zelf is altijd gewikkeld in een royale zijden doek (tomogire), die niet alleen helpt om de lakdoos in de tomobako te laten zinken of hem eruit te halen, maar die bovendien voorkomt dat de lakdoos in de tomobako teveel heen en weer kan schuiven. In de schrijfdoos zelf ligt gewoonlijk nog een dik zijden kussentje om te voorkomen dat het schrijfgerei of de waterdruppelaar zich in de lakdoos kunnen verplaatsen.

\section{Inkt}

Zou de heer Sakai de inkt voor de Chinese inscriptie in deze schrijfdoos hebben aangemaakt? Hoe ging dit dan in zijn werk?

De inkt wordt gemaakt met een inktblok en water. Het inktblok (sumi) bestaat uit plantaardig roet, dat eerst samen met eeen dieklijke lijm als/2023 01:18:22 PM 
deeg gekneed en vervolgens in een vorm geperst is alvorens het te drogen wordt gelegd. Vaak hebben de inktblokken een reliëfversiering, waaraan niet zelden wat bladgoud te pas is gekomen. Een inktblok van goede kwaliteit kan vele jaren meegaan.

Om de inkt te produceren wordt eerst een kleine hoeveelheid water uit de waterdruppelaar (suiteki) op het vlakke gedeelte van de inktsteen (suzuri) gegoten. Daarna wordt het inktblok loodrecht op de vochtige inktsteen gezet en stevig geschuurd tot de inkt de gewenste dikte heeft gekregen. De inkt verzamelt zich in het verdiepte gedeelte van de inktsteen. Als het penseel in de inkt gedoopt wordt, kan het schrijven of kalligraferen beginnen.

In deze luxe schrijfdoos bevindt zich een inktblokhouder, die zwarte handen bij het aanmaken van de inkt voorkomt - al geven goede inktblokken niet af. Het mesje wordt gebruikt om het papier op maat te snijden. Met de prikker kan een gaatje in het vel papier worden gemaakt om dit aan andere vellen papier of bijvoorbeeld aan een betekenisvol bloesemtakje vast te binden en dan aan geliefde, vriend of familielid te schenken (afb. 7).

Hoewel in het Westen de term schrijfdoos gangbaar is geworden, heet

Afb. 7

Het schrijfgerei met een inktblok dit type doos in Japan eigenlijk 'inktsteendoos' of suzuribako (suzuri = inktsteen; hako = doos), wat de belangrijkste functie, het aanmaken van inkt, benadrukt.

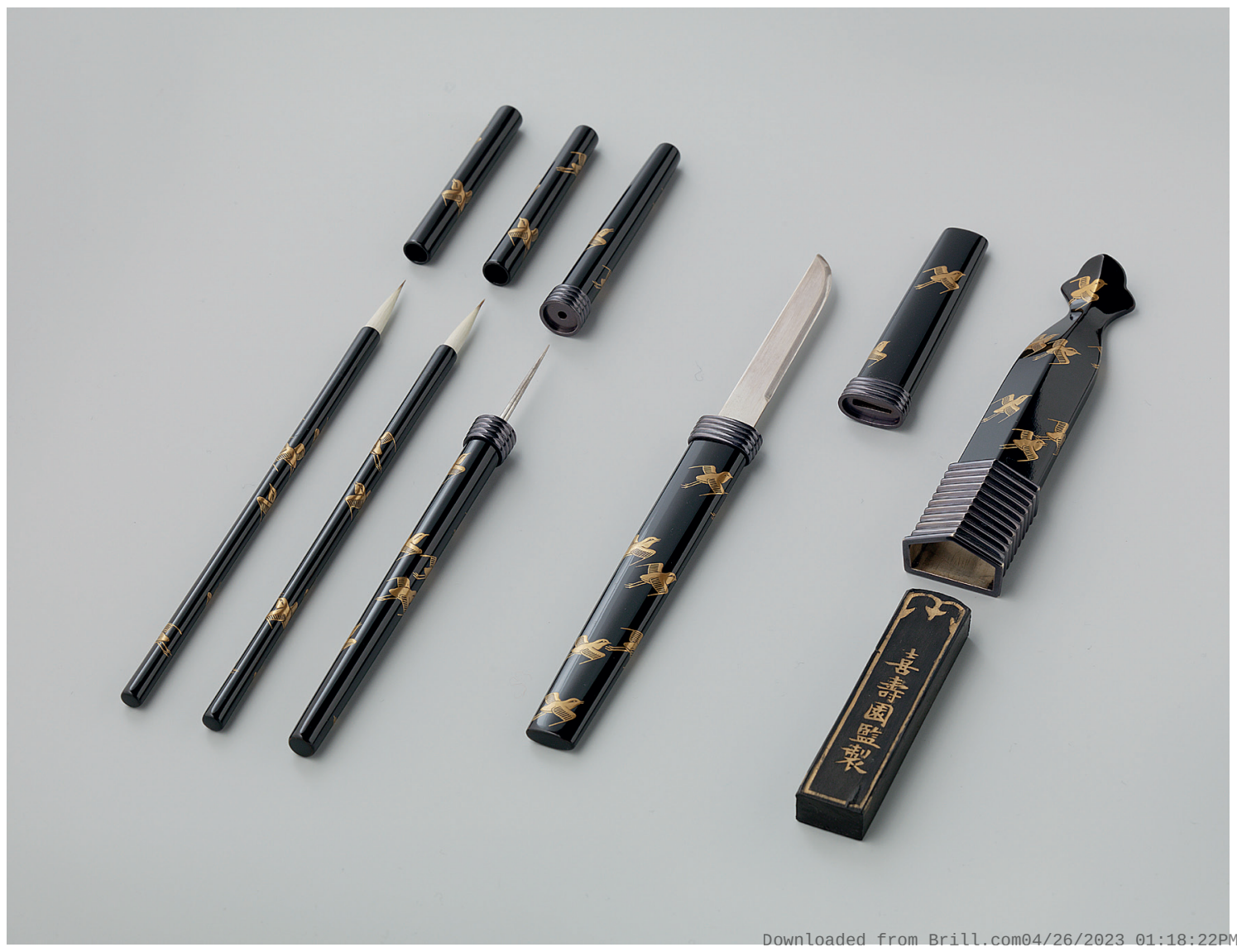




\section{Uono Jisei}

Uono Jisei was afkomstig uit de provincie Ishikawa, die al honderden jaren bekend staat om zijn mooie lakwerk. Waarschijnlijk heeft hij daar de beginselen van het ambacht onder de knie gekregen om nadien in de leer te gaan bij Akatsuka Jitoku in Tokyo. Vervolgens vestigde hij zich in Kyoto en omgeving om tenslotte in de oorlogsjaren naar zijn geboortegrond terug te keren. De schrijfdoos Jonge pijnboomloten heeft hij ongetwijfeld in Kyoto gemaakt.

De waterdruppelaar is het werk van de zilversmid Nagasaka Kōei (I885I965), die wel vaker aan Jisei leverde. Wellicht heeft hij ook de zilveren randen van het schrijfgerei vervaardigd.

Wat Uono Jisei met deze doos lijkt te willen zeggen is, dat er door een goed doordacht ontwerp met eenvoudige, maar perfect uitgevoerde laktechnieken een indrukwekkend resultaat te behalen is.

- In 1975 is Jan Dees geboeid geraakt door de lakkunst van Japan. Naast zijn werk als gastro-enteroloog verricht hij sinds de late jaren 80 in Europa en Japan onderzoek naar lakkunstenaars uit de periode I890-1950. Hieruit is in 2007 het proefschrift Facing Modern Times: The Revival of Japanese Lacquer Art I890I950 voortgekomen.

\section{NOTEN}

* De foto's van alle lakobjecten, die in deze reeks besproken zijn, werden gemaakt door Frans Pegt van het Rijksmuseum.

I Henri Kerlen vertaalde de Chinese tekst op de binnenkant van de bewaardoos.

2 Direct zonlicht is bijzonder schadelijk voor lakwerk. De bekende verzamelaar Edward Wrangham vertelde mij eens dat een van zijn lakdozen in een uur tijd zijn glans verloren had door blootstelling aan direct zonlicht.

\section{REEKS LAKDOZEN DOOR JAN DEES (OP VOLGORDE VAN PUBLICATIE):}

'De Hōraizan schrijfdoos van Uono Jisei, of: hoe een saai thema toch een aantrekkelijk ontwerp kan opleveren ', Aziatische Kunst 44/2 (20I4), pp. 43-48.

'De schrijfdoos Herfstplanten van Dōmoto Gosaborō', Aziatische Kunst 44/3 (2014), pp. II-I5. [incl. overzicht 3 belangrijkste makie technieken.]

'De schrijfdoos Het geluid der dingen', Aziatische Kunst 45/I (2015), pp. I9-23.

'De sieradendoos Stilte van de nacht van Miyoshi Kagari', Aziatische Kunst 45/2 (2015), pp. 19-25.

'De schrijfdoos Kannon met de wilgentak', Aziatische Kunst 45/3 (2015), pp. 13-23.

'De schrijfdoos Bidsprinkhaan van Uematsu Hōbi', Aziatische Kunst 46/I (2016), pp. I9-27. [incl. verklarende woordenlijst.]

'De Erwtenplant schrijf \& papierdoos van Moriya Shōtei', Aziatische Kunst 46/2 (2016), pp. 29-35.

'De schrijfdoos Jonge pijnboomloten van Uono Jisei', Aziatische Kunst 46/3 (2016), pp. 3I-38. 